\title{
Hamburguesas de lentejas
}

\section{Lentil hamburger}

\author{
Alejandra Avila Cid ${ }^{a}$, Tania Hernández Sánchez ${ }^{b}$, Elsa Nathalie Barranco Ángeles ${ }^{c}$
}

\begin{abstract}
:
Functional Foods can be natural or modified, adding or eliminating components to increase their benefits to the health of those who consume. Achieving that by the advancements of biotechnology are enriched by micronutrients, that is, vitamins and minerals.

The Characteristics of Functional breath are the following:

- They are part of a daily diet.

- Consuming does not cause damage to health.

- Improvement for those who consume.

- Helps in disease prevention.

- Existence of studies that are certified show that consuming brings benefits to health.

One of the most popular and consumed dishes in recent times is the Hamburger. Traditionally its structure starts with a bun, beef or pork, vegetables and cheese. Considering that lentils are a healthy source of energy and protein for the body are combined with shitake mushrooms which allow to obtain a balanced content of amino acids that benefits the health of the consumer.
\end{abstract}

Keywords:

Health, Functional breath, Chronic diseases, Balanced diet

\section{Resumen:}

Los alimentos funcionales pueden ser naturales o modificados, añadiendo o eliminado algún componente para incrementar sus beneficios a la salud de quienes los consuman, logrando que por medio de los avances en la biotecnología sean enriquecidos en micronutrientes, es decir, vitaminas y minerales.

Las características de un aliento funcional son las siguientes:

- Forman parte de la alimentación diaria.

- Su consumo no ocasiona daños a la salud.

- Mejora la salud de quien los consume.

- Ayuda en la prevención de enfermedades

- Existencia de estudios que certifiquen que su consumo trae beneficios a la salud.

Uno de los platillos más populares y consumidos en los últimos tiempos es la hamburguesa, tradicionalmente se estructura a partir de un bollo, carne de res y/o cerdo, vegetales y queso; considerando que la lenteja constituye una saludable fuente de energía y de proteínas para el organismo, combinadas con los hongos shitake permiten obtener un equilibrado contenido en aminoácidos esenciales que benefician potencialmente la salud del consumidor.

\section{Palabras Clave:}

Salud, Alimentos funcionales, Enfermedades crónicas, Alimentación equilibrada

\footnotetext{
a Profesor de asignatura del programa educativo de gastronomía, Autor de correspondencia, Universidad Autónoma del Estado de Hidalgo, Instituto de Ciencias Económico Administrativas, https://orcid.org/0000-0002-8367-8997,Email: alejandra_avila@uaeh.edu.mx b Profesor de asignatura del programa educativo de gastronomía, Universidad Autónoma del Estado de Hidalgo, https://orcid.org/0000-00022119-8381, Email: tania.hernandez@uaeh.edu.mx

${ }^{c}$ Profesor de asignatura del programa educativo de gastronomía, Universidad Autónoma del Estado de Hidalgo, https://orcid.org/0000 -00015485-6259, Email: elsa_barranco9313@uaeh.edu.mx
} 


\section{Introducción}

De acuerdo a la investigación de "Alimentos funcionales" realizada por la Organización médica Colegial de España, el concepto surge en los años 80's en Japón, con el fin de implementar una estrategia para mejor la calidad de vida de sus habitantes y reducir el riesgo de contraer enfermedades. [1]

Debido al interés de la población en general acerca de los beneficios de llevar una dieta saludable se ha incrementado en los últimos tiempos la demanda de información acerca de este tema, así como avances tecnológicos en nutrición y genómica.

Se considera un alimento funcional a todos aquellos que están presentes en dietas normales o de consumo diario y común, dependiendo del territorio donde se habite y las condicione de su suelo, es decir, alimentos naturales que no han sido industrializados o procesados artificialmente para su consumo, por lo cual se puede expresar que los alimentos funcionales se caracterizan por tener componentes biológicamente activos que traen beneficios a la salud y reducen el riesgo de padecer enfermedades crónicas.

La alimentación equilibrada que incorpora en la dieta diaria alimentos funcionales, ligado a un estilo de vida saludable, ofrece la posibilidad de mejorar la salud y prevención de algunas enfermedades. Algunos ejemplos de estos alimentos son las frutas, verduras, soja y leche. [2]

Actualmente la implementación de alimentos funcionales es tan importante que los profesionales de la salud han puesto en marcha su uso como una media alterna y complementaria en los tratamientos médicos tradicionales, pues la ciencia ha demostrado las funciones de estos alimentos y su beneficio para el consumidor. [3]

\section{Nombre de la Práctica}

Hamburguesa de lentejas

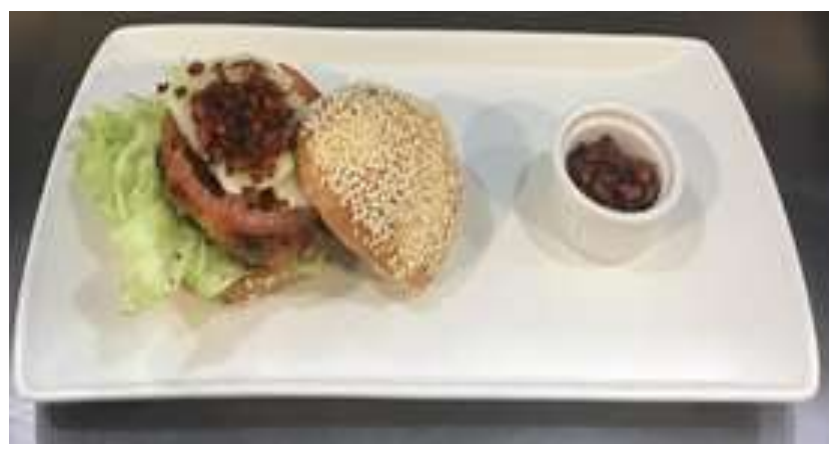

Imagen 1. Hamburguesa de lentejas. Autoría propia

\section{Insumos Requeridos para su realización [4]}

\begin{tabular}{|c|c|c|}
\hline Ingredientes & Cantidad & Unidad \\
\hline Lentejas rojas & 0.050 & $\mathrm{Kg}$ \\
\hline Hongos shitake & 0.050 & $\mathrm{Kg}$ \\
\hline Frutos secos naturales & 0.015 & $\mathrm{Kg}$ \\
\hline Flor de sal & 0.001 & $\mathrm{Kg}$ \\
\hline Aceitunas negras & 0.005 & $\mathrm{Kg}$ \\
\hline Arroz & 0.020 & $\mathrm{Kg}$ \\
\hline Pan rallado & 0.010 & $\mathrm{Kg}$ \\
\hline Ajo en polvo & 0.001 & $\mathrm{Kg}$ \\
\hline Cebolla en polvo & 0.001 & $\mathrm{Kg}$ \\
\hline $\begin{array}{l}\text { Pan integral de } \\
\text { hamburguesa }\end{array}$ & 1 & Pza \\
\hline Lechuga francesa & $1 / 4$ & Pza \\
\hline Jitomate & 0.020 & $\mathrm{Kg}$ \\
\hline Chorizo vegano & 0.060 & $\mathrm{Kg}$ \\
\hline Queso provolone & 0.050 & $\mathrm{Kg}$ \\
\hline Aceite vegetal & 0.100 & $\mathrm{~L}$ \\
\hline Pimienta & 0.005 & $\mathrm{Kg}$ \\
\hline
\end{tabular}

Tabla1. Ingredientes de hamburguesa de lentejas

\section{Procedimiento}

Mise en place

1. Lavar y desinfectar las hortalizas.

2. Remojar las lentejas durante 3 horas.

3. Hidrata los hongos shitake durante 30 minutos. 
1. Hervir la lentejas hasta suavisar.

2. Cocer el arroz hasta suavisar.

3. Freír el chorizo.

4. Moler las lentenjas, los hongos, frutos secos, pan molido y arroz.

5. Sazonar con sal, pimienta, ajo y cebolla

6. Moldear la "carne" de lentejas y cocerla con poco aceite.

7. Montar la hamburguesa poniendo el una cama de lechuga, "carne" de lentejas, queso, chorizo, jitomate y aceitunas sobre el bollo.

Utensilios

Satén, procesador de alimentos, mortero.

\section{Conclusiones}

La inclusión de alimentos funcionales en una dieta común ayuda al organismo a disminuir y/o prevenir el riesgo de contraer ciertas enfermedades. Los cereales constituyen una buena combinación con las legumbres, por ejemplo, el bollo integral con las lentejas rojas; por otra parte la suma del hongo shitake

\section{Referencias}

[1]Rodríguez Vicente, J. M. y otros, 2011. Consejo General de Colegios Oficiales de Médicos. [En línea] Available at: https://www.cgcom.es/sites/default/files/gbpc aliment os funcionales.pdf

[Último acceso: 09 septiembre 2020].

[2]Cervera, P., Clapés, J. \& Rigolfas, 2004. Alimentacion y Dietoterapia (Nutrición aplicada en salud y en la enfermedad). 4 ed. España: McGraw-Hill Interamericana.

[3]Peréz-Lizaur, A. B. \& Marván-Laborde, L., 2005. Manual de Dietas Normales y Terapéuticas. Los Alimentos en Salud y en la Enfermedad. 5 ed. México: Ediciones científicas, La Prensa Médica Mexicana.

[4]UAEH, 2020. mnual de prácticas de cocina de cuidados especiales. México: UAEH. 